\title{
Sources of Human Non-Typhoid Salmonellosis: A Review
}

\section{Author(s)}

Freitas Neto OC de

Penha Filho RAC 2

Barrow $\mathrm{P}^{3}$

Berchieri Junior $A^{4}$

1,2,4 Universidade Estadual Paulista "Julio de Mesquita Filho"- campus de Jaboticabal Departamento de Patologia Veterinária.

3 The University of Nottingham

School of Veterinary Medicine and Science

Mail Address

E-mail: oliveirocaetano@yahoo.com.br

Keywords

Antimicrobial resistance, beef, food, pork, poultry, Salmonella spp., vegetables,

\section{ABSTRACT}

Salmonellosis is a worldwide disease caused by bacteria of the genus Salmonella. Currently, there are over 2,500 identified serovars of Salmonella. A reduced number of these serovars, about eighty, are implicated in most animals and human diseases. Most cases of salmonellosis in humans are associated with the consumption of contaminated food products such as beef, pork, poultry meat, eggs, vegetables, juices and other kind of foods. It may also be associated with the contact between humans and infected pet animals. Therefore, the chain of human salmonellosis is very complex and in most cases the origin of the infection is difficult to establish. The use of antimicrobial agents to treat and to prevent bacterial infections in humans and animals, as well as as growth promoters in animal production, has favoured the selection and transference of resistance genes between different bacteria, including Salmonella serovars. Many studies have confirmed the role of foods of animal origin as a source of multi drugresistant Salmonella serovars. For this reason, continuous surveillance of these pathogens along the food chain together with the responsible use of antimicrobial agents is necessary.

\section{BACKGROUND}

The bacteria of the genus Salmonella are spread worldwide and are responsible for illnesses in human beings and animals. Currently, the genus is divided into two species, Salmonella enterica and Salmonella bongori (Popoff \& Minor 2001). S. enterica is divided into six subspecies (enterica, salamae, arizonae, diarizonae, houtenae and indica), each of which has several serovars or serotypes (Table 1). Thus, a serotype is nominated in the following way: Salmonella enterica subspecies enterica serotype Typhimurium, which may be simplified as Salmonella Typhimurium. Nowadays, more than 2,500 serotypes are known and most of them (almost 1,500) belong to subspecies enterica (Porwollik et al., 2004; CDC, 2007c).

\begin{tabular}{lccccccc}
\hline Table 1. Distribution of serovars by Salmonella species. & \multicolumn{1}{c}{ S. } \\
\cline { 2 - 7 } $\begin{array}{l}\text { Species } \\
\text { Subspecies }\end{array}$ & enterica & salamae arizonae diarizonae houtenae & indica & bongori \\
\hline Number of Serovars & 1490 & 500 & 94 & 329 & 72 & 12 & 22 \\
\hline
\end{tabular}

Salmonellosis is the disease caused by Salmonella serovars. A few serotypes are host-specific. Salmonella Pullorum and Gallinarum are responsible for pullorum disease and fowl typhoid in poultry, respectively, $S$. Typhi for typhoid fever in human beings, S. Dublin for disease in bovine, etc. However, the others are not host-specific and may infect several animal species including human beings. These serotypes are generally responsible for food-borne diseases and foods of animal origin are the 
main source. Historically, S. Typhimurium is the most common agent of human food-borne disease, although in the last few decades $S$. Enteritidis has become more common (Braden, 2006; Fernandes et al., 2006). Among all the 2,500 serovars, about eighty are most frequently involved in animal and human salmonellosis. S. Typhimurium and S. Enteritidis are the most common agents of disease in human beings and animals, but there is also increasing concern about the Infantis, Agona, Hadar, Heidelberg, and Virchow Salmonella serotypes.

Salmonellosis is one of the most important human food-borne diseases. Improvements in the quality of life as a result of hygienic conditions and sewage treatment have helped to prevent typhoid fever, and its occurrence is now frequently related to bad weather conditions like storms resulting in contamination of drinking water with sewage. The world population has increased dramatically, and to address the demand for food it has been necessary to increase production in large scale intensive farms. In these conditions, enteric pathogens like Salmonella serovars that have non-specific hosts, once introduced on farms may easily become disseminated among animals, resulting in persistence. Once this happens, it becomes almost impossible to eradicate the pathogens from farms and to eliminate them from products used as food or for preparing foods. To give an idea of the complexity of the chain of food-borne salmonellosis, at the beginning of the 1970s, many cases of human salmonellosis caused by Salmonella Agona in Europe and in the United States of America were associated with the ingestion of broiler meat from flocks fed with feed containing fish meal from Peru (Clark et al., 1973). Since the 1980s, worldwide outbreaks of human salmonellosis have been caused by S. Enteritidis present in eggs and contaminated broiler meal. In this case, breeders and laying hens were often thought to be infected by rodent feces and urine and transmitted the bacterium vertically, resulting in infected progeny. In addition, during the same period, outbreaks of human salmonellosis, resulting from ingestion of pork and beef meat contaminated with Salmonella serovars, have been reported in many countries (CDC, 1981; Spitalny et al., 1984; Delpech et al., 1998), with S. Typhimurium being the main serotype involved. Pork and beef were probably contaminated during the slaughter process followed by inadequate cooking.

Despite the strong link between food of animal origin and human salmonellosis, people may be infected by other ways, such as by cross contamination at home and commercial kitchens, through contact with other people, pets - especially dogs, cats and reptiles, as well as by ingestion of vegetables and fruits. This review attempts to provide information about different sources of Salmonella serovars which may be involved in human salmonellosis outbreaks. In addition, a basic knowledge about antimicrobial resistance in Salmonella serovars isolated from foods of animal origin is also presented since many drugs are used frequently in animal production.

\section{Red meat and red-meat products as a source of Salmonella serovars for human beings}

Red meat and red-meat products are recognized as an important source of human salmonellosis. Only in 2007, for instance, beef and pork (and products thereof) contaminated with Salmonella serovars were responsible for 800 cases of human salmonellosis involving 37 outbreaks in Europe (EFSA, 2009).

Additionally, in 2005, Hess et al. (2008) reported that lamb's liver was responsible for an outbreak of $S$. Typhimurium phage type 197 in Australia. In Germany, from 2001 to 2005, epidemiological studies, microbiological testing, and trace-back investigations showed that pork and pork products were involved in human salmonellosis outbreaks (Jansen et al., 2007). Moreover, in Italy, an outbreak of $S$. Typhimurium phage type DT 104A involving 63 cases was reported. In this study, a case-control study was conducted and data were analyzed by multivariate analysis. No food samples were available for testing; however, in northern Italy, two months prior to the outbreak, the veterinary surveillance system identified the first isolation of S. Typhimurium DT104A in a pig. Both human (patients) and pig isolates showed indistinguishable pulsed-field gel electrophoresis (PFGE) patterns. It was not possible to trace the pig after the sample collection. The results of the case-control study suggested that the consumption of pork salami was associated with this outbreak, underlining the importance of good manufacturing practices for readyto-eat foods (Luzzi et al., 2007).

In Denmark an outbreak of human salmonellosis caused by S. Typhimurium DT 104 occurred between July and August 2005, and the comparison of strains from patients and food using PFGE, tandem repeat analysis (MLVA), and antibiogram tests showed that the source of the outbreak was imported beef served as carpaccio (Ethelberg et al., 2007). Some months later there was an increase in the number of $S$. 
Typhimurium DT 104 cases in the Netherlands (Kivi et al., 2007). These occurrences were found to be epidemiologically associated with the disease in Denmark. A case-control study was conducted with 56 cases and 100 controls, and logistic regression analysis was used for analyzing the results (Ethelberg et al., 2007). From this investigation beef was considered the most probable vehicle of $S$. Typhimurium DT 104. Complementary assessment suggested that imported beef from a third European country had spread this Salmonella strain resulting in these outbreaks.

In the USA in 2004, an epidemiological investigation demonstrated that ground beef sold by a national chain of one supermarket was the source of food-borne salmonellosis due to $S$. Typhimurium in nine states. The PFGE patterns of $S$. Typhimurium isolates from patients and ground beef were found to be identical (CDC, 2006).

Many other reports involving human salmonellosis outbreaks associated with consumption of red meat have been recorded in the literature (CDC, 1995a; Davies et al., 1996; Roels et al., 1997; Shapiro et al., 1999; Haeghebaert et al., 2001). In most of cases, the disease was associated with the consumption of contaminated meat or as a result of incorrect or inadequate cooking.

\section{Human non-typhoid salmonellosis caused by the ingestion of dairy products}

Salmonella serovars are widespread in the environment and may contaminate a variety of food and food ingredients. Since dairy products are from animal origin, they may also be implicated in human food-borne salmonellosis. Usually milk and milk products are submitted to pasteurization, which kills Salmonella serovars. Milk-borne salmonellosis is therefore often related to the consumption of raw or inadequately pasteurized milk. However, Salmonella serovars may also contaminate dairy products after the pasteurization process.

S. Typhimurium caused an outbreak in Pennsylvania, USA, in 2007, through the consumption of raw milk. S. Typhimurium isolated from human and milk exhibited suspect identical PFGE patterns. Later, an epidemiological investigation confirmed that the source of $S$. Typhimurium was the raw milk and raw milk products from a dairy (CDC, 2007e). An outbreak of $S$. Newport in the USA in 2008 occurred predominantly among Hispanics in northeastern Illinois. S. Newport was recovered from patients and from a Mexican-style aged cheese made with unpasteurized milk (CDC, 2008c). The strains isolated from people and cheese had indistinguishable PFGE patterns. Another outbreak of human salmonellosis associated with cheese was described in Switzerland, Europe, where a nationwide outbreak of gastrointestinal disease caused by $S$. Stanley, a rare serovar in Europe, occurred from September 2006 to February 2007. S. Stanley strain was isolated from a local soft cheese and from 94\% of affected people. The withdrawal of the cheese from the market resolved the problem (Pastore et al., 2008).

In view of the great number of human salmonellosis associated to the consumption of powdered milk products registered in the 1960's and 1970's, Salmonella control criteria were included in the Codex of Hygienic Practice for Foods for infants and children (Codex, 1979). Between 1985 and 2005 at least six outbreaks of salmonellosis, involving up to 250 infants, have been associated with powdered infant formula. For example, in 2005 in France, an outbreak affecting more than 100 infants was associated with powdered infant formula contaminated with S. Agona. Many of these outbreaks were identified because the Salmonella strains were unique in some way (e.g. a rare serovar). Another common feature of the outbreaks was the low level of Salmonella contamination detected in the implicated formula (Salmonella serovars may be missed in routine testing). These outbreaks likely represent only a small proportion of the actual number of Salmonella infections in infants that have been linked to powdered infant formula (Toyofuku et al., 2006; Cahill et al., 2008).

\section{Salmonella serovars in foods from vegetable origin: a matter of increasing concern}

In recent years, the importance of foods of vegetable origin as potential vehicles of gastrointestinal infection has been highlighted. During production, storage or even in retail outlets, Salmonella serovars may contaminate vegetables, fruits, juices, and, as they are usually consumed raw, they may also be implicated in human salmonellosis.

Unpasteurized orange juice was responsible for food-borne salmonellosis in 152 people in six states in the USA between May and July 2005 (Jain et al., 2009). Vojdani et al. (2008) reviewed fruit juice-associated outbreaks of illness reported to Centers for Disease Control and Prevention (CDC), in Atlanta, USA. From 1995 through 2005, 21 juice-associated outbreaks were 
reported to CDC; ten implicated apple juice or cider, eight were linked to orange juice, and three implicated other types of fruit juice. These outbreaks caused 1,366 illnesses, with a average of 21 cases per outbreak (range, 2 to 398 cases). Among the 13 outbreaks of known etiology, five were caused by Salmonella serovars.

Three cases of S. Thompson infection were registered by the Norwegian reference laboratory in November 2004. The results of the investigation indicated that the consumption of rucola lettuce and mixed salad were responsible for the outbreak (Nygård et al., 2008).

In addition, Little \& Gillespie (2008) described general outbreaks of infectious intestinal disease linked to prepared salads reported in England and Wales from 1992 to 2006, as well as European outbreaks associated with prepared salads as a result of international trade. According to the authors, around $23 \%$ of these outbreaks were attributed to Salmonella serovars. Cross-contamination, infected food handler or inappropriate storage were the most commonly factors associated with vegetable contamination.

In 2002 tomatoes, grown and packed in Virginia state (USA), contaminated with $S$. Newport, caused illness in 510 patients in 26 other states (Kretsinger et al., 2003). Later, in July-November 2005, the same strain (confirmed by PFGE) caused illness in at least 72 patients in 16 states of the USA. A case-control study during the 2005 outbreak confirmed tomatoes as the source. The tomatoes were traced back to Virginia, where the $S$. Newport strain was isolated from pond water used to irrigate tomato fields, suggesting persistent contamination of the fields (Greene et al., 2008). In addition, during 2005-2006, three more outbreaks of Salmonella infections associated with eating tomatoes were detected in the USA and Canada. These outbreaks resulted in 387 cultureconfirmed cases of salmonellosis, with isolation of $S$. Newport, S. Braenderup, and S. Typhimurium (CDC, 2007b).

Unicomb et al. (2005) described human salmonellosis outbreaks associated with sesame seed-based food. In November 2002, an outbreak of S. Montevideo occured in New South Wales, Australia. Infected persons were interviewed, and epidemiologically linked retail outlets inspected. Imported "tahini", a sesame seed-based food, was rapidly identified as the source of infection. A second outbreak was identified in Australia in June-July 2003 and another in New Zealand in August 2003. Of a total of 68 patients infected by S. Montevideo, 66 were contacted. Fiftyfour $(82 \%)$ reported consumption of sesame seedbased foods. Laboratory analyses demonstrated closely related PFGE patterns in the $S$. Montevideo isolates from human cases and sesame-based foods imported from two countries.

Although it is known that fresh salad vegetables, herbs, seeds and fruit may become contaminated from environmental sources, they have been associated only recently with food-borne diseases. Nowadays, the role of vegetables as vehicle for pathogens transmission has become clear and recurrent, demonstrating that major health problems can arise from consumption of contaminated vegetables if hygiene practices break down.

\section{Pets as a source of Salmonella infection for human beings}

Many pet animals can harbor and shed Salmonella serovars. The close contact between pets and people, especially children and immunosuppressed people, can result in human salmonellosis. Animals commonly infected with Salmonella serovars which may pose a risk to humans include amphibians, birds, cats, dogs, fish, guinea pigs, hamsters, horses, mice, rabbits, lizards, snakes, and turtles, although, according to literature reports, the last three (lizards, snakes, and turtles) are responsible for the majority of human salmonellosis outbreaks associated with pets (CDC, 2005; Bruins et al., 2006; Corrente et al., 2006; CDC, 2007f; Bertrand et al., 2008; CDC, 2008a ).

The association of reptiles with human salmonellosis was first described in the 1950s (Boycott et al., 1953). Since then, reports have become more frequent. According to Mermin et al. (2004), approximately 1.4 million human cases of Salmonella infection occur each year in the USA and it has been estimated that 74,000 are the result of exposure to pet reptiles and amphibians. From 1994 to 1995, thirteen health state agencies in the USA reported to CDC human infection cases caused by uncommon Salmonella serovars, in which the patients had had direct or indirect contact with reptiles (snakes, lizards and turtles). In most cases, the same Salmonella serovar was isolated from the patient and from the reptile (CDC, 1995b). In 2005, at least six cases of human salmonellosis were associated with pet turtles in two states of the USA (CDC, 2005). Also in the USA, in October 2007, the North Carolina Division of Public Health notified to CDC human infections caused by S. Paratyphi B var. Java in several states. The results of the epidemiological and 
laboratory investigations showed that many of these infections occurred in young children and were associated with exposure to small turtles (CDC, 2008a).

A survey with the purpose of estimating the role of pet reptiles in human salmonellosis was done in Europe (Bertrand et al., 2008). In one study, in 2007-2008 seven human salmonellosis cases in Belgian were described which were related to contact with turtles and snakes. The same survey reported three reptileassociated cases of Salmonella infection in the past three years in France: two cases in 2005 and one, imported from China, in 2006. The patients were all young children, aged eight months, three years and four years, respectively. They were infected with a multi-resistant strain of $S$. Typhimurium. The first two cases had contact with, respectively, a snake and an iguana; in the third case an indirect link to a turtle (consumption of turtle soup) was found. At least 14 cases of human salmonellosis associated with reptile contact were identified in Ireland between 2005 and 2008, and 31 cases, also associated with reptiles, were reported in Germany during 2006-2008. Although infections in adults from contact with reptiles have been reported, in most cases infants less than one year old are affected.

In most countries, although cases of salmonellosis are reported within the national surveillance system, the source of infection is not routinely given, and the possible exposure to pet animals is usually only revealed in additional epidemiological investigations. Thus, the true number of cases due to direct or indirect contact with pet animals is likely underestimated.

\section{Other sources of Salmonella for human beings}

In some cases, salmonellosis may be associated with uncommon sources. It is frequently the result of factors including the ubiquitous distribution of Salmonella serovars, usage of contaminated ingredients, incorrect cleaning or disinfection of equipment in the food industry, and infected employees working in restaurant kitchens.

In the USA, an outbreak caused by a Salmonella strain with a specific PFGE pattern occurred during January 1-December 31, 2007. In this outbreak, a total of 401 cases from 41 states were identified and 32\% of ill persons were hospitalized. A case-control study indicated that illness was associated with consumption of not-ready-to-eat pot pies. Later, the outbreak strain was isolated from 13 samples of unopened pot pies collected from the homes of patients (CDC, 2008b).
Moreover, in November 2006, public health officials of CDC and state health departments detected an increase in the reported incidence of isolates of $S$. Tennessee. In a multi-state case-control study conducted during February 5-13, 2007, illness was demonstrated to be strongly associated with the consumption of two brands of peanut butter produced at the same process plant. A total of 628 persons infected with this outbreak strain of $S$. Tennessee had been reported from 47 states during 2006-2007 (CDC, 2007a). Later, on November 25, 2008, an epidemiological investigation began due to an increase of $S$. Typhimurium isolates that shared the same PFGE patters. Up to January 2009, 529 persons from 43 states from the USA and one person from Canada had been reported infected with this strain. A total of 116 patients were hospitalized, and the infection might have contributed to eight deaths. Sequential casecontrol studies indicated significant associations between illness and consumption of peanut butter, and specific brands of peanut butter biscuits. Epidemiological and laboratory findings indicated that peanut butter and peanut paste produced at one plant were the sources of the outbreak. These products were also ingredients in many foods produced and distributed by other companies. This outbreak highlights the complexities of "ingredient-driven" outbreaks and the importance of rapid outbreak detection and investigation (CDC, 2009).

On November 15, 2006, in the USA a case of salmonellosis in an employee of a poultry vaccine facility was notified. When a second case of salmonellosis in another employee at the same facility was reported on November 25, an outbreak investigation was initiated. Results of that investigation suggested that 21 employees of the facility became ill during a 1-month period from exposure to a strain of $S$. Enteritidis that was used in vaccine production. Infection was thought to have resulted from environmental contamination after the spill of a liquid containing a high concentration of $S$. Enteritidis. As a result, it was recommended that the facility improve its infection-control procedures to better protect workers. This outbreak highlights occupational risks that can be associated with the manufacture of veterinary biologicals derived from human pathogens (CDC, 2007d).

During October and November 2006, the Spanish National Reference Laboratory reported a series of isolations of $S$. Kottbus on the island of Gran Canaria. A matched case-control study was conducted and it showed that the ingestion of a brand of bottle water 
was related to outbreak. Microbiological and environmental analysis detected S. Kottbus in bottles randomly selected from markets, and also in the local factory where the water was bottled. A carrier pigeon loft was found near one water reservoir of the local factory and it could be verified that pigeons frequented this reservoir. Moreover, Salmonella spp. was detected in the pigeons, suggesting that they could be contaminating the water reservoir (Palmera-Suárez et al., 2007).

In 2002, an outbreak of $S$. Enteritidis phage-type 8 occurred at a convention center in Dallas, Texas, USA and continued for 6 weeks. From March to April, the hotel kitchen implicated catered for 41 multi-day conferences attended by 9,790 persons. A total of 617 illness reports from residents of 46 states were received. The epidemiological studies showed that sauces or items served with sauces were implicated in outbreak. Eleven food service employees, including one who prepared sauces, had stool cultures that yielded $S$. Enteritidis phage-type 8. Transmission ended with implementation of policies to screen food handlers and exclude those whose stool cultures yielded $S$. Enteritidis (Beatty et al., 2009).

In addition, in Germany, from October 2001 to March 2002 about 439 S. Oranienburg reports were registered. Simultaneously, an increase in this strain was noticed in other European countries. A casecontrol study was conducted, indicating that the consumption of chocolate from one company was associated with illness. Later, two brands from the same company were positive for $S$. Oranienburg. Isolates from humans and from chocolates had indistinguishable PFGE patters. No source or point of contamination was identified (Werber et al., 2005).

\section{Antibiotic resistance in Salmonella serovars: A serious problem in public health}

Since the start of the widespread use of antimicrobial agents by humans in the late 1940s, antibiotic resistance as a phenomenon has been observed in almost all bacterial species and against all drugs available. Antimicrobial resistance can increase the morbidity, mortality, and costs associated with disease. Moreover, it has social and economic consequences and requires strong scientific and public health efforts to improve the situation. The increase in the number of resistant and multiresistant (resistant to two and more antimicrobials) strains of bacteria has been recognized by the World Health Organization
(WHO) and health authorities as one of the major problems in public health (Helmuth, 2001).

The use of antibiotics in food animal production systems has resulted in emergence of antibiotic resistant zoonotic bacteria that can be transmitted to humans through the food chain (Walsh \& Fanning, 2008). Since the 1960s many studies have focused on this subject and the results are alarming. For instance, a rise in S. Typhimurium infection was observed in calves in United Kingdom during 1964-1966 following the adoption of the intensive farming methods (Anderson, 1968). A single phage type of $S$. Typhimurium, type 29, was incriminated as the major pathogen. Attempts to treat and control the disease with a range of antibiotics resulted in the acquisition of transferable multiple drug resistance by $S$. Typhimurium and the transmission of this strain, directly or indirectly, from bovines to man resulted in many human infections.

In Netherlands between 1972 and 1974, almost 50,000 Salmonella isolates from several sources (humans, animals, animal products, sewage, etc.) were tested for resistance to ampicillin, chloramphenicol, kanamycin, and tetracycline. In this study, the incidence of resistance to at least one of the above drugs ranged from $39.2 \%$ to $45.6 \%$. Moreover, many multidrugresistant strains of $S$. Typhimurium and $S$. Dublin were isolated from calves and cattle. In 1974, $64.4 \%$ of all strains of $S$. Typhimurium from these animals appeared to be resistant to ampicillin, tetracycline, chloramphenicol, and kanamycin, and $25.5 \%$ of $S$. Dublin were found to be resistant to chloramphenicol and tetracycline (Voogd et al., 1977).

Holmberg et al. (1984) assessed the origin of antimicrobial resistance in infections caused by Salmonella serovars in 52 outbreaks investigated by the CDC between 1971 and 1983. According to this study, in 38 outbreaks with identified source, food animals were involved in 11 (69\%) of 16 resistant and $6(46 \%)$ of 13 sensitive outbreak strains, S. Typhimurium being the main serovar isolated and beef and milk the main products involved. In addition, Cohen \& Tauxe (1986) analyzed the occurrence of antimicrobial resistance in Salmonella serovars in USA between 1960 and 1980, concluding that the use of antibiotics in animal husbandry played a major role in the emergence or persistence of these resistant Salmonella strains.

In 1989 an outbreak of S. Typhimurium DT 193 resistant to four antibiotics (ampicillin, streptomycin, sulphonamides, and tetracyclines) occurred in northern 
England, affecting 206 persons. An analytical study showed a significant association between illness and consumption of cold roast pork supplied by the butcher's shop. Later, S. Typhimurium DT 193 with the same antibiotic resistance pattern as the outbreak strain was isolated from samples of meat bought from the shop and from samples of pig feces taken from the farm supplying the shop. It was concluded that inadequate processing of infected pork meat at the shop may have contributed to this outbreak (Maguire et al., 1993).

Seyfarth et al. (1997) studied the frequency of antimicrobial resistance and epidemiological relatedness among 473 isolates of $S$. Typhimurium from human and veterinary sources in Denmark in 1993. In this study, the human strains were clinical isolates from patients with diarrhea (228 isolates) and animal strains were isolated from clinical or subclinical infections in cattle (48 isolates), pigs (99 isolates) and poultry (98 isolates). All strains were tested against 22 different antimicrobial agents used in both human and veterinary medicine with the disc diffusion method. Strains were also phage-typed and the plasmid content determined in all resistant strains. Of 228 human isolates tested, $19.3 \%$ of the strains were resistant to one or more antimicrobial agent compared with $10.4 \%$ of strains from cattle, $11.1 \%$ of strains from pigs and $9.2 \%$ of strains from poultry. Multiple resistance was found in $9.2 \%$ of the human strains, but in only two of the cattle isolates. Resistance in human strains was most common against tetracycline (13\%), ampicillin (12\%), sulphonamide $(12 \%)$, streptomycin $(10 \%)$, and chloramphenicol (8\%). The resistance pattern differed somewhat in animal isolates. Poultry strains were usually resistant only to ampicillin, while pig and cattle isolates were most often resistant to sulphonamide, tetracycline and streptomycin. Typing of the strains showed that some animal strains and human strains were indistinguishable.

Moreover, Molla et al. (1999) assessed the antimicrobial resistance to 10 drugs in 39 Salmonella serovars isolated from raw minced beef and chicken (gizzard, liver, and heart) samples in Addis Ababa (Ethiopia). Thirty four isolates (87.2\%) were resistant to one or more drugs. The antibiotics to which isolated strains were resistant included nitrofurantoin (48.7\%), furazolidone (48.7\%) and streptomycin (46.2\%). Only four antimicrobials (gentamycin, kanamycin, rifampicin, and sulphamethoxazole-trimethoprim) were effective against all isolateS. About $80 \%$ of the S. Enteritidis strains showed multiple resistance to up to four antibiotics followed by S. Typhimurium (60.0\%) and S. Dublin (33.3\%).

In 1997, a S. Typhimurium DT104 strain resistant to five antimicrobials (ampicillin, chloramphenicol, streptomycin, sulfonamides, and tetracycline) affected 110 people in two outbreaks in USA. A case-control study and laboratory investigations indicated an unpasteurized Mexican-style cheese as the responsible for these outbreaks (Cody et al., 1999).

White et al. (2001) identified and characterized strains of Salmonella isolated from ground chicken, beef, turkey, and pork purchased at three supermarkets of Washington, USA. The isolates were characterized by serotyping, antimicrobial-susceptibility testing, and phage-typing. Additionally, PCR and DNA sequencing were used to identify resistance integrons and extended spectrum beta-lactamase genes. Of 200 meat samples, $41(20 \%)$ were contaminated with 13 different serovars. Eighty four percent of the isolates were resistant to at least one antibiotic, and 53\% were resistant to at least three antibiotics. Sixteen percent of the isolates were resistant to ceftriaxone. Five isolates of $S$. Agona had resistance to 9 antibiotics, and the two isolates of S. Typhimurium DT208 were resistant to 12 antibiotics. Eighteen isolates, representing four serotypes, had integrons with genes conferring resistance to aminoglycosides, sulfonamides, trimethoprim, and beta-lactams.

In another study, Chen et al. (2004) analyzed 133 isolates of Salmonella serovars recovered from retail meats purchased in the USA and China, assessing the antimicrobial resistance of these strains. In this study, it was demonstrated that seventy-three $(82 \%)$ of these Salmonella serovars isolates were resistant to at least one antimicrobial agent. Resistance to the following antibiotics was common among the USA isolates: tetracycline $(68 \%$ of the isolates were resistant), streptomycin $(61 \%)$, sulfamethoxazole $(42 \%)$, and ampicillin (29\%). Eight Salmonella isolates (6\%) were resistant to ceftriaxone. Fourteen isolates $(11 \%)$ from China were resistant to nalidixic acid and displayed decreased susceptibility to ciprofloxacin. Moreover, Miko et al. (2005) determined antimicrobial resistance of Salmonella serovars isolated from German foodstuffs. A total of 319 epidemiologically independent multidrug-resistant isolates comprising 25 different serovars were tested for their antimicrobial susceptibility by broth microdilution. S. Typhimurium was the prevalent serovar, and it was isolated from beef and pork meat. The results of this study shown that the most prevalent resistances found in the multidrug- 
resistant Salmonella serovars from foods were to streptomycin (94\%), sulfamethoxazole (92\%), tetracycline $(81 \%)$, ampicillin $(73 \%)$, spectinomycin $(72 \%)$, chloramphenicol (48\%), and trimethoprim $(27 \%)$.

According to the USA Food and Drug Administration (FDA) (2006), in 2003, 22.5\% of non-typhoid Salmonella isolates from humans were resistant to at least one antimicrobial agent and the most common multidrugresistance phenotype reported was to ampicillin, chlorampheniol, streptomycin, sulfonamides, and tetracyclines, which was detected in $9.3 \%$ of isolates tested. While on the veterinary side, $44 \%$ of the Salmonella samples isolated from animal slaughter and veterinary diagnostic sources were resistant to at least one antimicrobial agent and the phenotype resistant to ampicillin, chlorampheniol, streptomycin, sulfonamides, and tetracyclines was also the most common multidrug resistance profile among veterinary isolates.

Between July 2004 and June 2005, a study was carried out in order to determine the prevalence and antimicrobial resistance of Salmonella serovars isolates from processed poultry in the USA. Four hundred eighty pre- and postchill whole broiler chicken carcasses were collected from a poultry processing plant. Water samples also were collected at the entrance and exit of the chiller. The proportions of pre- and postchill carcasses that were positive for Salmonella spp. were $88.4 \%$ and $84.1 \%$, respectively. Ninety-two percent of water samples collected at the entrance of the chiller were positive for Salmonella spp., but all exit water samples were negative. Additionally, Salmonella spp. isolated were serotyped and tested for susceptibility to antimicrobials. Thirteen serotypes were identified; the most common were S. Kentucky (59.5\%) and S. Typhimurium (17.8\%). Three hundred thirty-nine $(79.8 \%)$ of the isolates were resistant to at least one antimicrobial, and $53.4 \%$ were resistant to three or more antimicrobials. Resistance was most often observed to tetracycline (73.4\% of isolates), ampicillin $(52.9 \%)$, amoxicillin-clavulanic acid (52\%), ceftiofur $(51.7 \%)$, streptomycin (35.2\%), and sulfisoxazole $(21.8 \%)$. These results indicated that a large number of the isolates in poultry processing plants are frequently resistant to commonly used antimicrobials (Parveen et al., 2007).

Valdezate et al. (2007) conducted a study in order to determine the distribution and antimicrobial susceptibility of Salmonella serovars isolated in 2002 from food in 16 Spanish regions. Fifty one serovars were detected; the most common were $S$. Enteritidis and $S$. Typhimurium, followed by a group of 49 different serovars. The main sources of Salmonella serovars were eggs and their derivatives (21.6\% of strains), poultry and related products $(16.6 \%)$, and seafood $(16.3 \%)$. Resistance rates for S. Enteritidis, S. Typhimurium, and the group of 49 serovars were, respectively, 8.3, 69.8, and $13.9 \%$ for ampicillin, 3.1, 52.8 , and $59 \%$ for streptomycin, 40.6, 22.6, and $10.4 \%$ for nalidixic acid, 15.6, 71.7, and 31.1\% for tetracycline, 7.3, 18.8, and 9.5\% for trimethoprim-sulfamethoxazole, $0,50.9$, and $4.3 \%$ for chloramphenicol, and $6.2,71.7$, and $17.4 \%$ for multiple (at least four) antimicrobials. All the strains remained susceptible to other beta-lactams and fluoroquinolones.

From September 2003 to February 2004, Zewdu \& Cornelius (2009) assessed antimicrobial resistance of 98 isolates of Salmonella serovars recovered from food in Addis Ababa, Ethiopia. The results of this study revealed that 32 Salmonella isolates were resistant to one or more of the 24 antimicrobials tested. The most common resistance was to streptomycin $(75 \%)$, ampicillin (59.4\%), tetracycline $(46.9 \%)$, spectinomycin $(40.6 \%)$, and sulfisoxazole $(40.6 \%)$. The level of antimicrobial resistance was significantly higher for isolates from chicken carcass (62.1\%) and pork isolates (22.7\%).

In face of this public health problem, it is recommended a careful prescription of antimicrobial agents during veterinary practice, regardless of the purpose of this prescription (therapy, prophylaxis, and growth enhancement). This will increase the efficient use of antimicrobial agents after microbiological identification of the causative pathogen. Moreover, it is important to highlight that the use of any antimicrobial agent should not substitute good hygiene pratices and, wherever possible, alternative management methods should be sought and used. In addition, veterinarians should respect and follow the sanitary legislation concerning the use of antimicrobial agents in their country.

\section{Concluding remarks}

Members of the genus Salmonella are major enteric pathogens of human beings and animals. The increase of the human population and food production increases the potential for dissemination of these ubiquitous microorganisms. The high incidence of human nontyphoid salmonellosis demonstrates the potential harm of the presence of Salmonella in food and contact animals to people. In addition to disease caused by 
Salmonella serovars, antibiotic resistance can be transferred by other microorganisms that are agents of human disease similar to those involved in hospitalacquired infections. Fortunately, we can learn from undesirable episodes of life. The outbreaks of foodborne $S$. Enteritidis disease related to chickens from 1980 's trigged a great deal of discussion related to its control. As a result, in the understanding of the epidemiology of the infection in commercial birds improved. Thus, monitoring program could also be improved resulting in more efficient control programs in the food chain. In addition, nowadays there is an increasing worldwide preoccupation with the quality of the food; many countries have banned the use of antimicrobial agents in the feed and they are encouraging farmers to use non-harmful substances. All measures taken over animal husbandry may minimize the presence of Salmonella in food. However, the contribution of the consumers is also necessary by adopting the basic concepts of hygiene during food preparation and storing.

\section{References}

Anderson ES. Drug resistance in Salmonella typhimurium and its implications. British Medical Journal 1968; 3(5614):333-339.

Beatty ME, Shevick G, Shupe-Ricksecker K, Bannister E, Tulu A, Lancaster K. et al. Large Salmonella Enteritidis outbreak with prolonged transmission attributed to an infected food handler, Texas, 2002. Epidemiolgy and Infection 2009; 137(3):417-427.

Bertrand S, Rimhanen-Finne R, Weill FX, Rabsch W, Thornton L, Perevoscikovs J, van Pelt W, Heck M. Salmonella infections associated with reptiles: the current situation in Europe. Euro Surveillance 2008; 13(24)

Boycott JA, Taylor J, Douglas SH. Salmonella in tortoiseS. The Journal of Pathology and Bacteriology 1953; 65(2):401-411.

Braden CR. Salmonella enterica Serotype Enteritidis and Eggs: A National Epidemic in the United StateS. Clinical Infectious Diseases: an official publication of the Infectious Diseases Society of America 2006; 43(4):512-517

Bruins MJ, de Boer AM, Ruijs GJ. Gastroenteritis caused by Salmonella from pet snakes. Nederlands Tijdschrift Voor Geneeskunde 2006; 150(41):2266-2269.

Cahill SM, Wachsmuth IK, Costarrica Mde L, Ben Embarek PK. Powdered infant formula as a source of Salmonella infection in infants. Clinical Infectious Diseases: an official publication of the Infectious Diseases Society of America 2008; 46(2):268-273.

CDC. Centers for Diseases Control and Prevention. Multiple outbreaks of salmonellosis associated with precooked roast beefPennsylvania, New York, Vermont. Morbidity and Mortality Weekly
Report 1981; 30(46):569-570.

CDC. Centers for Diseases Control and Prevention. Multistate outbreak of human Salmonella infections associated with exposure to turtles-United States, 2007-2008. Morbidity and Mortality Weekly Report 2008a; 57(3):69-72.

CDC. Centers for Diseases Control and Prevention. Multistate outbreak of Salmonella infections associated with frozen pot piesUnited States, 2007. Morbidity and Mortality Weekly Report 2008b; 57(47):1277-1280.

CDC. Centers for Diseases Control and Prevention. Multistate outbreak of Salmonella infections associated with peanut butter and peanut butter-containing products-United States, 2008-2009. Morbidity and Mortality Weekly Report 2009; 58(4):85-90.

CDC. Centers for Diseases Control and Prevention. Multistate outbreak of Salmonella serotype Tennessee infections associated with peanut butter-United States, 2006-2007. Morbidity and Mortality Weekly Report 2007a; 56(21):521-524.

CDC. Centers for Diseases Control and Prevention. Multistate outbreak of Salmonella Typhimurium infections associated with eating ground beef-United States, 2004. Morbidity and Mortality Weekly Report 2006; 55(7):180-182.

CDC. Centers for Diseases Control and Prevention. Multistate outbreaks of Salmonella infections associated with raw tomatoes eaten in restaurants-United States, 2005-2006. Morbidity and Mortality Weekly Report 2007b; 56(35):909-911.

CDC. Centers for Diseases Control and Prevention. Outbreak of multidrug-resistant Salmonella enterica serotype Newport infections associated with consumption of unpasteurized Mexican-style aged cheese-Illinois, March 2006-April 2007. Morbidity and Mortality Weekly Report 2008c; 57(16):432-435.

CDC. Centers for Diseases Control and Prevention. Outbreak of Salmonella serotype Typhimurium infection associated with eating raw ground beef-Wisconsin, 1994. Morbidity and Mortality Weekly Report 1995a; 44(49):905-909.

CDC. Centers for Diseases Control and Prevention. Reptileassociated salmonellosis-selected states, 1994-1995. Morbidity and Mortality Weekly Report 1995b; 44(17):347-350.

CDC. Centers for Diseases Control and Prevention. Salmonella: annual summary 2005. Atlanta, Georgia: US Department of Health and Human Services; 2007c [cited 2009 jul 14]. Available from: http://www.cdc.gov/ncidod/dbmd/phlisdata/salmtab/2005/ SalmonellaAnnualSummary2005.pdf.

CDC. Centers for Diseases Control and Prevention. Salmonella serotype Enteritidis infections among workers producing poultry vaccine-Maine, November-December 2006. Morbidity and Mortality Weekly Report 2007d; 56(34):877-879.

CDC. Centers for Diseases Control and Prevention. Salmonella Typhimurium infection associated with raw milk and cheese consumption-Pennsylvania, 2007. Morbidity and Mortality Weekly Report 2007e; 56(44):1161-1164. 
CDC. Centers for Diseases Control and Prevention. Salmonellosis associated with pet turtles--Wisconsin and Wyoming, 2004. Morbidity and Mortality Weekly Report 2005; 54(9):223-226.

CDC. Centers for Diseases Control and Prevention. Turtle-associated salmonellosis in humans-United States, 2006-2007. Morbidity and Mortality Weekly Report 2007f; 56(26):649-652.

Clark GM, Kaufmann AF, Gangarosa EJ, Thompson MA. Epidemiology of an international outbreak of Salmonella Agona. Lancet 1973; 2(7827):490-493.

Chen S, Zhao S, White DG, Schroeder CM, Lu R, Yang H, McDermott PF, Ayers S, Meng J. Characterization of multiple-antimicrobialresistant Salmonella serovars isolated from retail meatS. Applied and Environmental Microbiology 2004; 70(1):1-7.

Codex, 1979. Recommended International Code Of Hygienic Practice For Foods For Infants And Children CAC/RCP 21-1979 [cited 2009 jul 14]. Available from: http://www.euro.who.int/ document/fos/FoodsforlnfantsandChildren.pdf.

Cody SH, Abbott SL, Marfin AA, Schulz B, Wagner P, Robbins K, Mohle-Boetani JC, Vugia DJ. Two outbreaks of multidrug-resistant Salmonella serotype typhimurium DT104 infections linked to rawmilk cheese in Northern California. JAMA: the journal of the American Medical Association 1999; 281(19):1805-1810.

Cohen ML, Tauxe RV. Drug-resistant Salmonella in the United States: an epidemiologic perspective. Science 1986; 234(4779):964-969.

Corrente M, Totaro M, Martella V, Campolo M, Lorusso A, Ricci M, Buonavoglia C. Reptile-associated salmonellosis in man, Italy. Emerging Infectious Diseases 2006; 12(2):358-359.

Davies A, O'Neill P, Towers L, Cooke M. An outbreak of Salmonella typhimurium DT104 food poisoning associated with eating beef. Communicable Disease Report. CDR Review 1996; 6(11):159-162.

Delpech V, McAnulty J, Morgan K. A salmonellosis outbreak linked to internally contaminated pork meat. Australian and New Zealand Journal of Public Health 1998; 22(2):243-246.

EFSA. European Food Safety Authority. The Community Summary Report on Food-borne Outbreaks in the European Union in 2007. The EFSA Journal 2009; 271.

Ethelberg S, Sørensen G, Kristensen B, Christensen K, Krusell L, Hempel-Jørgensen A, Perge A, Nielsen EM. Outbreak with multiresistant Salmonella Typhimurium DT104 linked to carpaccio, Denmark, 2005. Epidemiology and Infection 2007; 135(6):900907.

Fernandes SA, Tavecchio AT, Ghiliardi AC, Dias AM, Almeida IA, Melo LC. Salmonella sorovars isolated from humans in São Paulo State, Brazil, 1996-2003. Revista do Instituto de Medicina Tropical de São Paulo 2006; 48:179-184.

FDA. US Food and Drug Administration. National Antimicrobial Resistance Monitoring System- Enteric Bacteria (NARMS): 2003 Executive report. Rockville, MD: US Department of Health and Human Services, FDA, 2006 [cited 2009 jul 14]. Available from:http:/
/www.fda.gov/downloads/AnimalVeterinary/SafetyHealth/ AntimicrobialResistance/ NationalAntimicrobialResistance MonitoringSystem/UCM061471.pdf.

Greene SK, Daly ER, Talbot EA, Demma LJ, Holzbauer S, Patel NJ, Hill TA, Walderhaug MO, Hoekstra RM, Lynch MF, Painter JA. Recurrent multistate outbreak of Salmonella Newport associated with tomatoes from contaminated fields, 2005. Epidemiology and Infection 2008; 136(2):157-165.

Haeghebaert S, Duché L, Gilles C, Masini B, Dubreuil M, Minet JC, Bouvet P, Grimont F, Delarocque Astagneau E, Vaillant V. Minced beef and human salmonellosis: review of the investigation of three outbreaks in France. Euro Surveillance 2001; 6(2):21-26.

Helmuth, R. Antibiotic Resistance in Salmonella. In: Wray C, Wray $A$, editor. Salmonella in domestic animalS. Wallingford: $C A B$ International; 2001. p. 89-106.

Hess IM, Neville LM, McCarthy R, Shadbolt CT, McAnulty JM. A Salmonella Typhimurium 197 outbreak linked to the consumption of lambs' liver in Sydney, NSW. Epidemiology and Infection 2008; 136(4):461-467.

Holmberg SD, Osterholm MT, Senger KA, Cohen ML. Drug-resistant Salmonella from animals fed antimicrobials. The New England Journal of Medicine 1984; 311(10):617-622.

Jain S, Bidol SA, Austin JL, Berl E, Elson F, Lemaile-Williams M, Deasy M 3rd, Moll ME, Rea V, Vojdani JD, Yu PA, Hoekstra RM, Braden CR, Lynch MF. Multistate outbreak of Salmonella Typhimurium and Saintpaul infections associated with unpasteurized orange juice--United States, 2005. Clinical Infectious Diseases: an official publication of the Infectious Diseases Society of America 2009; 48(8):1065-1071.

Jansen A, Frank C, Stark K. Pork and pork products as a source for human salmonellosis in Germany. Berliner und Münchener tierärztliche Wochenschrift 2007; 120(7-8):340-346.

Kivi M, Hofhuis A, Notermans DW, Wannet WJ, Heck ME, Van De Giessen AW, Van Duynhoven YT, Stenvers OF, Bosman A, Van Pelt W. A beef-associated outbreak of Salmonella Typhimurium DT104 in The Netherlands with implications for national and international policy. Epidemiology and Infection 2007; 135(6):890-899.

Kretsinger K, Noviello S, Moll M. Tomatoes sicken hundreds: multistate outbreak of Salmonella Newport. Proceedings of the 52nd Annual Epidemic Intelligence Service Conference; 2003; Atlanta, Georgia. USA.

Little CL, Gillespie IA. Prepared salads and public health. Journal of Applied Microbiology 2008; 105(6):1729-1743.

Luzzi I, Galetta P, Massari M, Rizzo C, Dionisi AM, Filetici E, Cawthorne A, Tozzi A, Argentieri M, Bilei S, Busani L, Gnesivo C, Pendenza A, Piccoli A, Napoli P, Loffredo L, Trinito MO, Santarelli E, Ciofi degli Atti ML. An Easter outbreak of Salmonella Typhimurium DT 104A associated with traditional pork salami in Italy. Euro Surveillance 2007; 12(4):11-12.

Maguire HC, Codd AA, Mackay VE, Rowe B, Mitchell E. A large 
Freitas Neto OC de, Penha Filho RAC, Barrow P, Berchieri Junior A outbreak of human salmonellosis traced to a local pig farm. Epidemiology and Infection 1993; 110(2):239-246.

Mermin J, Hutwagner L, Vugia D, Shallow S, Daily P, Bender J. Reptiles, amphibians and human Salmonella infection: a populationbased, case-control study. Clinical infectious diseases: an official publication of the Infectious Diseases Society of America 2004; 38 Suppl 3:S253-261.

Miko A, Pries K, Schroeter A, Helmuth R. Molecular mechanisms of resistance in multidrug-resistant serovars of Salmonella enterica isolated from foods in Germany. The Journal of Antimicrobial Chemotherapy 2005; 56(6):1025-1033.

Molla B, Kleer J, Sinell HJ Antibiotic resistance pattern of foodborne Salmonella isolates in Addis Ababa (Ethiopia). Berliner und Münchener tierärztliche Wochenschrift 1999; 112(2):41-43.

Nygård K, Lassen J, Vold L, Andersson Y, Fisher I, Löfdahl S, Threlfall J, Luzzi I, Peters T, Hampton M, Torpdahl M, Kapperud G, Aavitsland P. Outbreak of Salmonella Thompson infections linked to imported rucola lettuce. Foodborne Pathogens and Disease 2008; 5(2):165173.

Palmera-Suárez R, García P, García A, Barrasa A, Herrera D. Salmonella Kottbus outbreak in infants in Gran Canaria (Spain), caused by bottled water, August-November 2006. Euro Surveillance 2007; 12(7):E070712.2.

Parveen S, Taabodi M, Schwarz JG, Oscar TP, Harter-Dennis J, White DG. Prevalence and antimicrobial resistance of Salmonella recovered from processed poultry. Journal of Food Protection 2007; 70(11):2466-2472.

Pastore R, Schmid H, Altpeter E, Baumgartner A, Hächler H, Imhof $R$, Sudre P, Boubaker K. Outbreak of Salmonella serovar Stanley infections in Switzerland linked to locally produced soft cheese, September 2006 - February 2007. Euro Surveillance 2008; 13(37): 18979.

Popoff MY, Minor L. Antigenic formulae of the Salmonella serovars. 8th ed. Paris: WHO Collaborating Center for Reference and Research on Salmonella; 2001.

Porwollik S, Boyd EF, Choy C, Cheng P, Florea L, Proctor E. Characterization of Salmonella enterica subspecies I genovars by use of microarrayS. Journal of Bacteriology 2004; 186(17):58835898.

Roels TH, Frazak PA, Kazmierczak JJ, Mackenzie WR, Proctor ME, Kurzynski TA, Davis JP. Incomplete sanitation of a meat grinder and ingestion of raw ground beef: contributing factors to a large outbreak of Salmonella Typhimurium infection. Epidemiology and Infection 1997; 119(2):127-134.

Seyfarth AM, Wegener HC, Frimodt-Møller N. Antimicrobial resistance in Salmonella enterica subsp. enterica serovar Typhimurium from humans and production animals. The Journal of Antimicrobial Chemotherapy 1997; 40(1):67-75.

Shapiro R, Ackers ML, Lance S, Rabbani M, Schaefer L, Daugherty J, Thelen C, Swerdlow D. Salmonella Thompson associated with

\section{Sources of Human Non-Typhoid Salmonellosis: A Review}

improper handling of roast beef at a restaurant in Sioux Falls, South Dakota. Journal of Food Protection 1999; 62(2):118-122.

Spitalny KC, Okowitz EN, Vogt RL. Salmonellosis outbreak at a Vermont hospital. The Southern Medical Journal 1984; 77(2):168172.

Toyofuku H, Kubota K, Morikawa K. Outbreaks of Salmonella in infants associated with powdered infant formula. Bulletin of National Institute of Health Sciences 2006; 124:74-79.

Unicomb LE, Simmons G, Merritt T, Gregory J, Nicol C, Jelfs P, Kirk M, Tan A, Thomson R, Adamopoulos J, Little CL, Currie A, Dalton $C B$. Sesame seed products contaminated with Salmonella: three outbreaks associated with tahini. Epidemiology and Infection 2005; 133(6):1065-1072.

Valdezate S, Arroyo M, González-Sanz R, Ramíro R, Herrera-León S, Usera MA, De la Fuente M, Echeita A. Antimicrobial resistance and phage and molecular typing of Salmonella strains isolated from food for human consumption in Spain. Journal of Food Protection 2007; 70(12):2741-2748.

Vojdani JD, Beuchat LR, Tauxe RV. Juice-associated outbreaks of human illness in the United States, 1995 through 2005. Journal of Food Protection 2008; 71(2):356-364.

Voogd CE, van Leeuwen WJ, Guinée PA, Manten A, Valkenburg JJ. Incidence of resistance to ampicillin, chloramphenicol, kanamycin and tetracycline among Salmonella species isolated in the Netherlands in 1972, 1973 and 1974. Antonie van Leeuwenhoek 1977; 43(3-4):269-281.

Walsh C, Fanning S. Antimicrobial resistance in foodborne pathogens--a cause for concern?. Current Drug Targets 2008; 9(9):808-815.

Werber D, Dreesman J, Feil F, van Treeck U, Fell G, Ethelberg S, et al. International outbreak of Salmonella Oranienburg due to German chocolate. BMC Infectious Diseases 2005; 5(1):7.

White DG, Zhao S, Sudler R, Ayers S, Friedman S, Chen S, McDermott PF, McDermott S, Wagner DD, Meng J. The isolation of antibioticresistant Salmonella from retail ground meatS. The New England Journal of Medicine 2001; 345(16):1147-1154.

Zewdu E, Cornelius P. Antimicrobial resistance pattern of Salmonella serotypes isolated from food items and personnel in Addis Ababa, Ethiopia. Tropical Animal Health and Production 2009; 41(2):241249. 